\title{
Design and Evaluation of Ionic Liquids as Novel $\mathrm{CO}_{2}$ Absorbents
}

Quarterly Technical Report

Reporting Period Start Date: 10/01/04

Reporting Period End Date: 12/31/04

Principal Author: Prof. Edward J. Maginn

Report Issued: January 31, 2005

DOE Award Number: DE-FG26-04NT42122

University of Notre Dame

511 Main Building

Notre Dame, IN 46556 


\section{Disclaimer}

This report was prepared as an account of work sponsored by an agency of the United States Government. Neither the United States Government nor any agency thereof, nor any of their employees, makes any warranty, express or implied, or assumes any legal liability or responsibility for the accuracy, completeness, or usefulness of any information, apparatus, product, or process disclosed, or represents that its use would not infringe privately owned rights. Reference herein to any specific commercial product, process, or service by trade name, trademark, manufacturer, or otherwise does not necessarily constitute or imply its endorsement, recommendation, or favoring by the United States Government or any agency thereof. The views and opinions of authors expressed herein do not necessarily state or reflect those of the United States Government or any agency thereof. 


\section{Abstract}

Progress from the second quarter of activity on the project "Design and Evaluation of Ionic Liquids as Novel $\mathrm{CO}_{2}$ Absorbents” is provided. Major activities in three areas are reported: compound synthesis, property measurement and molecular modeling.

Two new ionic liquid compounds have been synthesized and characterized. Viscosities, densities and gas solubilities have been measured for several of the ionic liquids synthesized during Q1. Continued progress on computational modeling of the ionic liquids has been made. 


\section{Table of Contents}

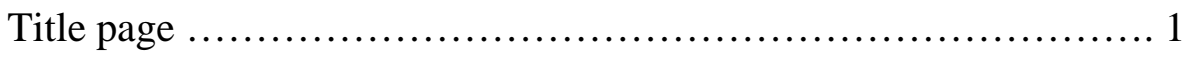

Disclaimer .................................................. 2

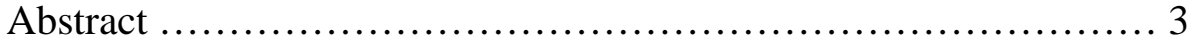

Table of Contents ............................................... 4

List of Graphical Materials ..................................... 5

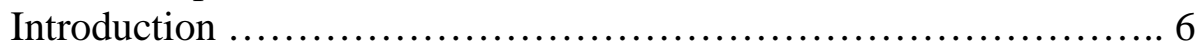

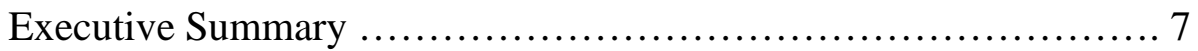

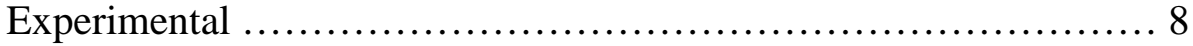

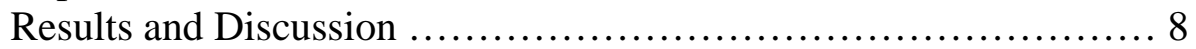

Conclusions .................................................. 14

References .............................................. 15 


\section{List of Graphical Materials}

Figure 1: List of most recently synthesized ionic liquids.

Figure 2: ${ }^{1} \mathrm{H}$ NMR trace of [hmim][lactate].

Figure 3: Viscosity as a function of temperature for several new ionic liquids.

Figure 4: Density as a function of temperature for five new ionic liquids.

Figure 5: Graphical representation of Henry’s Law constants for several gases. 


\section{Introduction}

Ionic liquids are a new and exciting class of compound that have the potential to overcome many of the problems associated with current $\mathrm{CO}_{2}$-capture techniques. Ionic liquids (ILs) are organic salts that are liquid in their pure state near ambient conditions. ILs are regarded as potentially environmentally-benign solvents due to their immeasurably low vapor pressure, which essentially eliminates the opportunity for solvent release to the atmosphere.

The goal of this project is to obtain a fundamental understanding of the solubility of $\mathrm{CO}_{2}$ and other components present in flue gas in ILs, with the practical objective of tailoring the properties of the liquid to maximize the engineering properties for this process. Our plan is to do this through a combination of synthesis and experimental measurements, molecular simulation and applications development. This second quarterly technical report describes the results of our work on this project from 10/01/2004 through the end of the second quarter $(12 / 31 / 04)$. 


\section{Executive Summary}

Ionic liquids (ILs) are organic salts that are liquid in their pure state near ambient conditions. They are a new and exciting class of compound that have the potential to overcome many of the problems associated with current $\mathrm{CO}_{2}$-capture techniques. This project is concerned with developing a fundamental understanding of the solubility of flue gas species (mainly $\mathrm{CO}_{2}$ ) in ionic liquids. Using this knowledge, we hope to develop new IL compounds that can be used in a cost effective manner for $\mathrm{CO}_{2}$ capture. During the second quarter of the project, we have undertaken three major activities: compound synthesis and characterization, physical property measurement and molecular modeling.

\section{Compound Synthesis and Characterization}

Since October, attempts to synthesize and purify six new ILs have been made. Two of these compounds ([hmim][lactate] and [hmim][methylmalonate]) have been purified and characterized by NMR. The other compounds, including $\left[\mathrm{H}_{2} \mathrm{NC}_{3} \mathrm{H}_{6} \mathrm{mim}\right]\left[\mathrm{Tf}_{2} \mathrm{~N}\right]$, $\left[\mathrm{H}_{2} \mathrm{NC}_{3} \mathrm{H}_{6} \mathrm{mmim}\right]\left[\mathrm{Tf}_{2} \mathrm{~N}\right],\left[\mathrm{Et}_{2} \mathrm{Nic}\right]\left[\mathrm{EtSO}_{4}\right]$ and $\left[\mathrm{H}_{3} \mathrm{NC}_{3} \mathrm{H}_{6} \mathrm{DMAP}\right]\left[\mathrm{Tf}_{2} \mathrm{~N}\right]_{2}$ have been made but are either still impure or other technical problems have prevented the successful synthesis of sufficient quantities for making physical property measurement.

\section{Physical Property Measurement}

The viscosities of ten ionic liquids (most from the Q1 synthesis efforts) have been measured. Gas solubility measurements have been made for five different ionic liquids with carbon dioxide, methane, ethane, ethylene, oxygen, nitrogen and hydrogen. The density of five new ionic liquids has been measured as a function of temperature.

\section{Molecular Modeling}

A new type of simulation method that enables gas absorption isotherms to be simulated is under development. Most of the effort in this area during Q2 was spent on code development and testing. 


\section{Experimental}

Compounds were synthesized using standard wet chemical methods described in our previous publications (Anthony et al., 2001; Aki et al., 2005). Densities were measured using a calibrated pycnometer. Gas absorption was measured using a gravimetric microbalance, as described in our previous publications (Anthony et al., 2001; Macedonia et al., 2000).

\section{Results and Discussion}

\section{Compound Synthesis}

Since October, attempts to synthesize and purify six new ILs have been made (figure 1). The [hmim][lactate] and [hmim][methylmalonate] have been purified and characterized by NMR. The halide and silver content have been measured on the [hmim][lactate] along with ${ }^{1} \mathrm{H}$ NMR. The ${ }^{1} \mathrm{H}$ NMR for [hmim][lactate] is shown in figure 2. The [hmim][methylmalonate] has been characterized by ${ }^{1} \mathrm{H}$ NMR, MS, and EA. The analysis shows that there is some residual nitrate still present in the compound. Depending on the batch, the amount of nitrogen varies from $~ 10-40 \%$. Attempt to synthesis and purify compounds based on Bates et al (2001) work are in various stages. The $\left[\mathrm{H}_{2} \mathrm{NC}_{3} \mathrm{H}_{6}\right.$ mim] $\left[\mathrm{Tf}_{2} \mathrm{~N}\right]$ has not been sufficiently purified for further study. The compound quickly degrades. The $\left[\mathrm{H}_{2} \mathrm{NC}_{3} \mathrm{H}_{6} \mathrm{mmim}\right]\left[\mathrm{Tf}_{2} \mathrm{~N}\right]$ has been synthesized, but in very small quantity. Additional material is being made. It does not decompose as quickly, but impurities from the synthetic process still need to be removed. The $\left[\mathrm{H}_{3} \mathrm{NC}_{3} \mathrm{H}_{6} \mathrm{DMAP}\right]\left[\mathrm{Tf}_{2} \mathrm{~N}\right]_{2}$ is water-soluble so it has not been possible to separate the compound from the lithium bromide. 


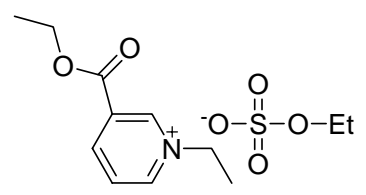

$\left[\mathrm{Et}_{2} \mathrm{Nic}\right]\left[\mathrm{EtSO}_{4}\right]$

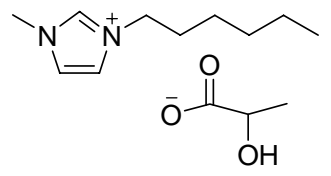

[hmim][lactate]

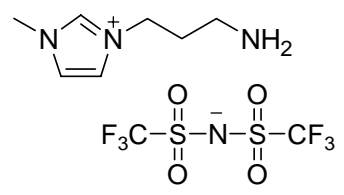

$\left[\mathrm{H}_{2} \mathrm{NC}_{3} \mathrm{H}_{6} \operatorname{mim}\right]\left[\mathrm{Tf}_{2} \mathrm{~N}\right]$

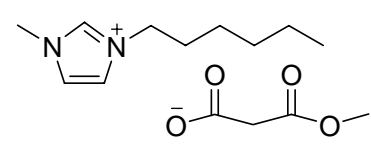

[hmim][methymalonate]

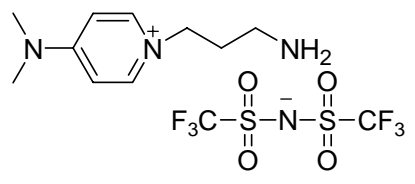

$\left[\mathrm{H}_{2} \mathrm{NC}_{3} \mathrm{H}_{6} \mathrm{DMAP}\right]\left[\mathrm{Tf}_{2} \mathrm{~N}\right]$

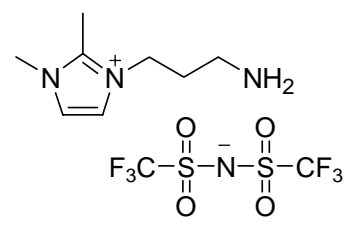

$\left[\mathrm{H}_{2} \mathrm{NC}_{3} \mathrm{H}_{6} \mathrm{mmim}\right]\left[\mathrm{Tf}_{2} \mathrm{~N}\right]$

Figure 1: Most recently synthesized ILs 

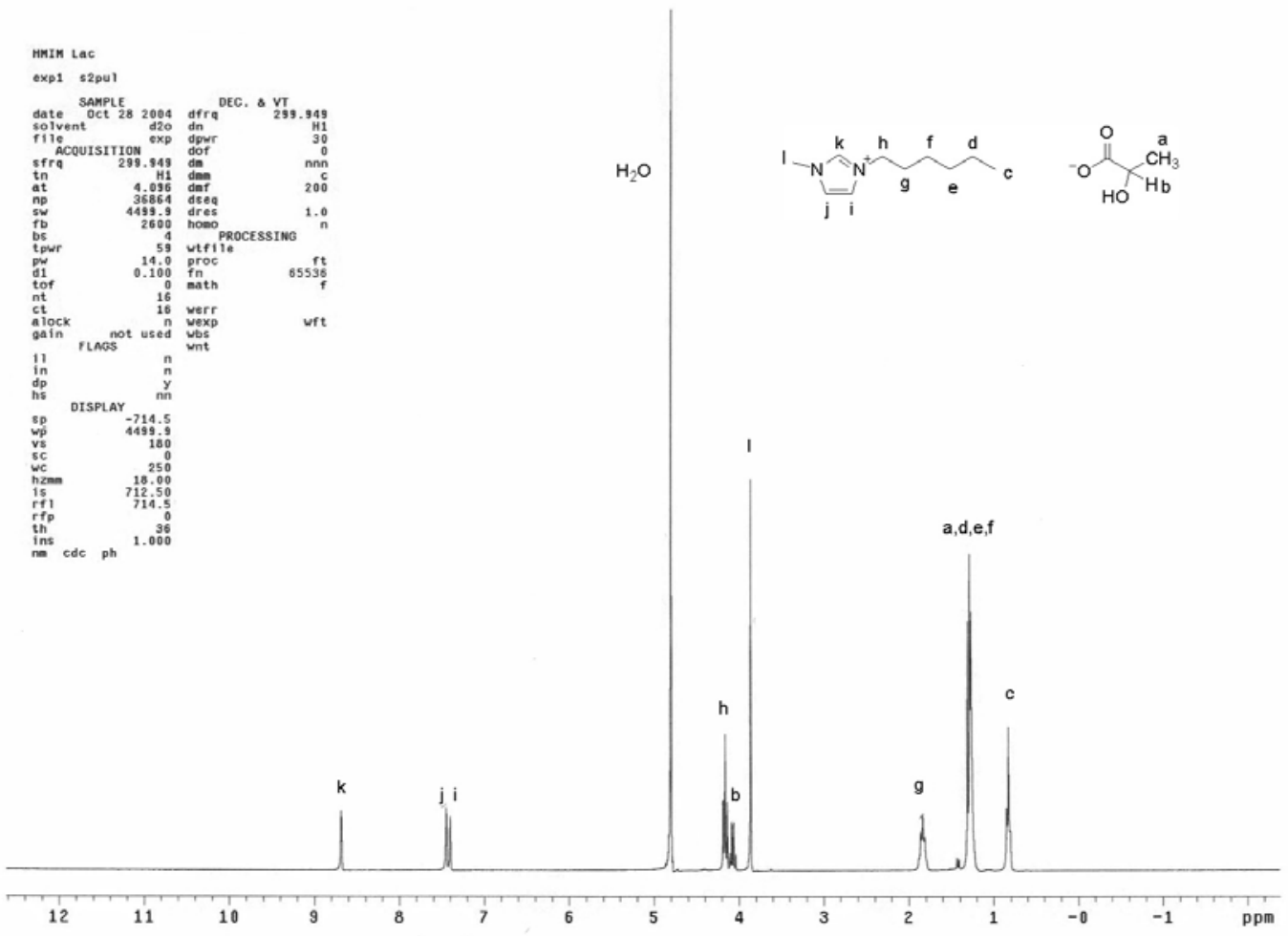

Figure 2: ${ }^{1} \mathrm{H}$ NMR of [hmim][lactate].

\section{Property Measurement}

The viscosities of several of the ionic liquids used in the capture of $\mathrm{CO}_{2}$ have been measured. The water content of the IL at the time the viscosity was measured is included for most of the ILs in Table 1. The [hmim][lactate] did not have the water run at the time the viscosity was run due to problems with the Karl Fisher unit at the time of the experiments. The sample will need to be redried and the viscosity run before the water can be taken. It is reasonable to expect the water levels at the viscosities listed in the table that the water content is close to that of the $\left[\right.$ bimim] $\left[\mathrm{CH}_{3} \mathrm{CO}_{2}\right]$. The lactate anion should have a similar affinity to water as the acetate. The presence of water or other solvents can have an effect on the viscosity of the ionic liquid. A visual comparison of some of the ILs measured can be found in figure 3. All of the ILs were placed on a vacuum line for at least 48 hours with heating, ranging from $40-70{ }^{\circ} \mathrm{C}$, to dry them before measuring the viscosities. 
Table 1: Viscosity and water content for various ILs.

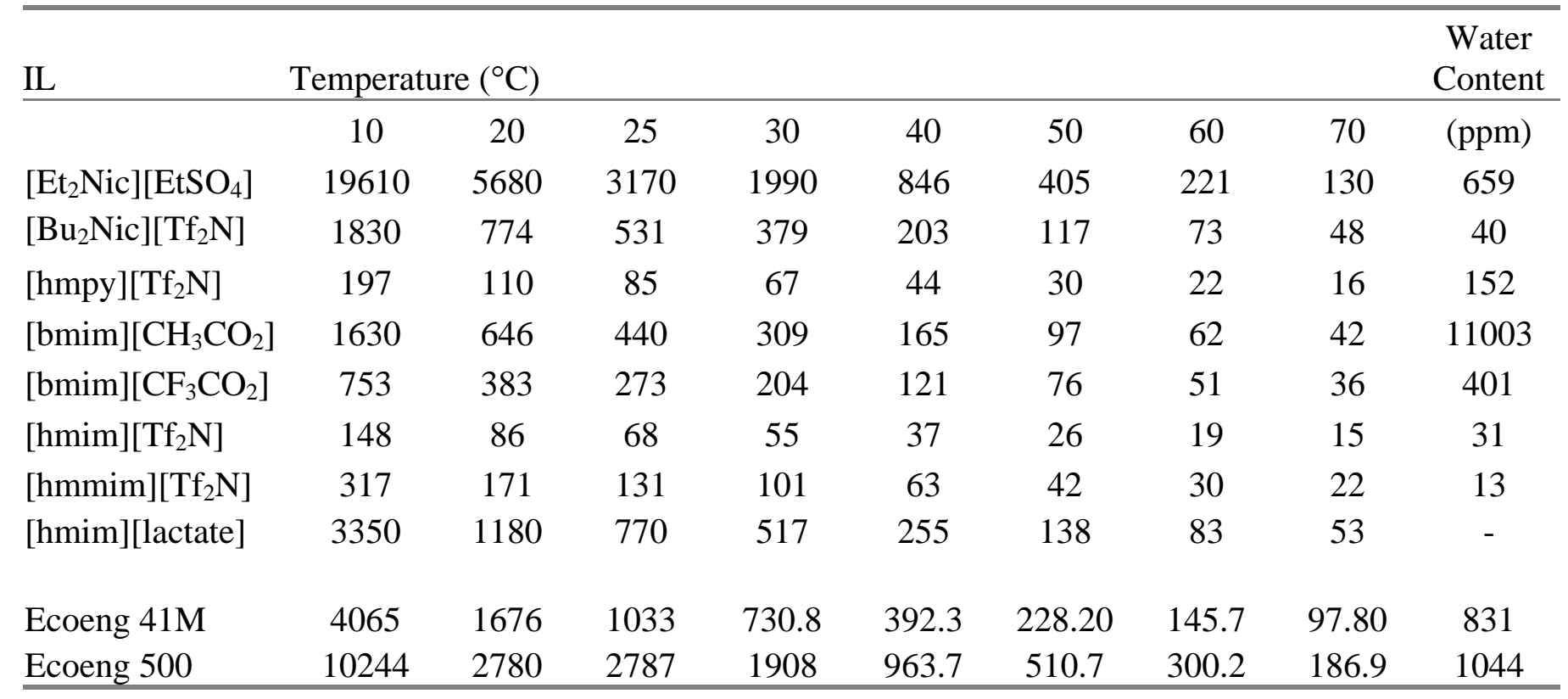

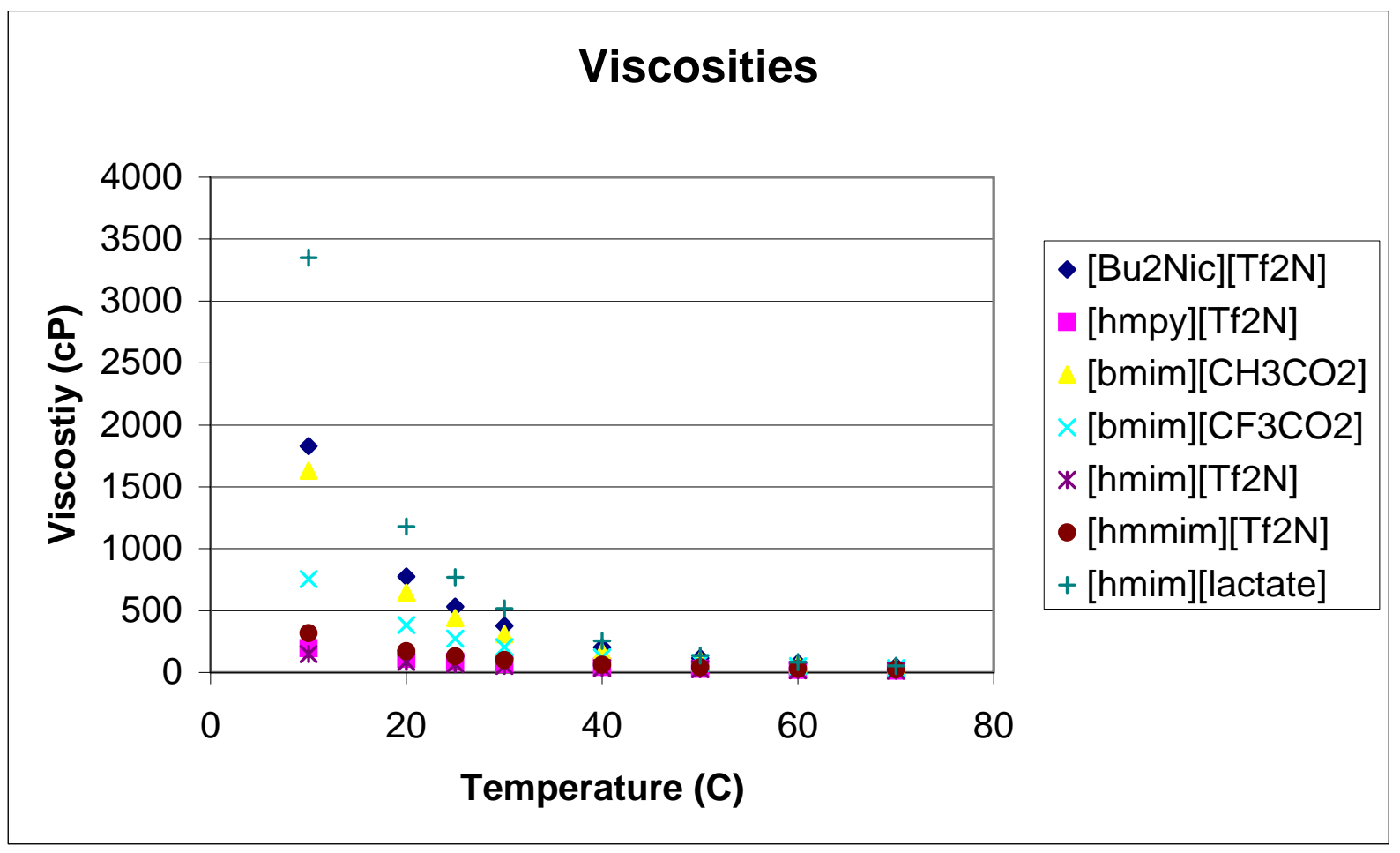

Figure 3: Viscosity as a function of temperature for several new ionic liquids. 
Densities were also measured as a function of temperature for five new ionic liquids. The procedure involved the use of a pycnometer, and was described in previous reports. Table 2 shows the results of the experiments, with Figure 4 presenting the data in graphical format.

Table 2: Various IL densities with error

\begin{tabular}{|c|c|c|c|}
\hline $\mathrm{IL}$ & Density linear fit & $\begin{array}{c}\text { Density } \\
\text { Error }\end{array}$ & $\begin{array}{c}\text { Density at 250C } \\
\text { (g/cc) }\end{array}$ \\
\hline$[$ bmim][acetate] & $-4.92 \mathrm{E}-4^{*} \mathrm{~T}(\mathrm{oC})+1.0773$ & 0.00131 & 1.0650 \\
\hline$[$ hexafluoroimid][Tf2N] & $-1.16 \mathrm{E}-3^{*} \mathrm{~T}(\mathrm{oC})+1.72$ & 0.00139 & 1.6910 \\
\hline$[\mathrm{hmim}][\mathrm{eFAP}]$ & $-1.11 \mathrm{E}-3^{*} \mathrm{~T}(\mathrm{oC})+1.585$ & 0.00065 & 1.5573 \\
\hline$[\mathrm{hmim}][\mathrm{Tf} 2 \mathrm{~N}]$ & $-9.63 \mathrm{E}-4^{*} \mathrm{~T}(\mathrm{oC})+1.402$ & 0.00345 & 1.3779 \\
\hline$[\mathrm{hmpy}][\mathrm{Tf} 2 \mathrm{~N}]$ & $-9.11 \mathrm{E}-4^{*} \mathrm{~T}(\mathrm{oC})+1.408$ & 0.00456 & 1.3852 \\
\hline
\end{tabular}

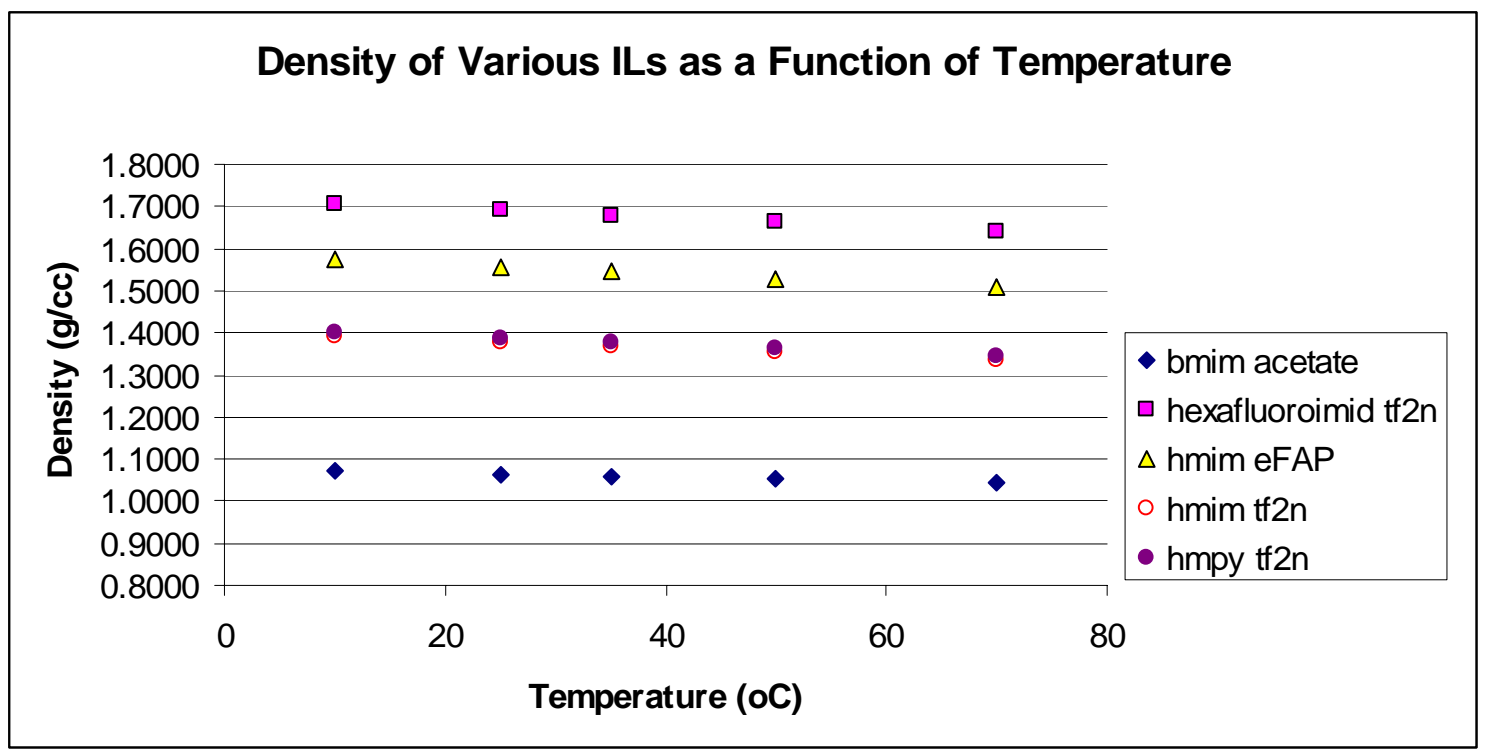

Figure 4: Density as a function of temperature for five new ionic liquids.

Gas solubilities, in the form of isotherms and Henry's Law constants, were measured using the gravimetric microbalance described in our earlier report. The enthalpy and entropy of absorption were determined from the temperature dependence of the Henry's Law constants. Tabular results are given in Table 3, while a graphical representation of the Henry's Law constants is in Figure 5. Note the order of magnitude higher solubility of $\mathrm{CO}_{2}$ compared to $\mathrm{O}_{2}$ and the hydrocarbons. 
Table 3: Henry's Law constants and enthalpy and entropy of absorption for various ionic liquids.

\begin{tabular}{|c|c|c|c|c|c|}
\hline \multirow[b]{2}{*}{ Ionic Liquid } & \multicolumn{3}{|c|}{$\mathrm{H}$ (bar) } & \multirow{2}{*}{$\begin{array}{l}\text { Enthalpy } \\
(\mathrm{kJ} / \mathrm{mol})\end{array}$} & \multirow{2}{*}{$\begin{array}{c}\text { Entropy } \\
(\mathrm{J} / \mathrm{mol} \mathrm{K})\end{array}$} \\
\hline & $10 \operatorname{deg} C$ & $25 \operatorname{deg} C$ & 50 degC & & \\
\hline \multicolumn{6}{|c|}{ Carbon Dioxide } \\
\hline$[\mathrm{hmpy}]\left[\mathrm{Tf}_{2} \mathrm{~N}\right]$ & $25.3 \pm 1.5$ & $32.7 \pm 0.7$ & $46.1 \pm 0.4$ & $-11.1 \pm 0.7$ & $-36.0 \pm 2.1$ \\
\hline$[\mathrm{hmim}]\left[\mathrm{Tf}_{2} \mathrm{~N}\right]$ & $24.2 \pm 0.9$ & $31.6 \pm 0.4$ & $45.6 \pm 0.4$ & $-11.8 \pm 0.5$ & $-38.4 \pm 1.5$ \\
\hline [hmim][eFAP] & & $25.3 \pm 0.3$ & $42.9 \pm 0.7(600 \mathrm{C})$ & undetermined & undetermined \\
\hline [hexafluoroimid][ $\left[\mathrm{Tf}_{2} \mathrm{~N}\right]$ & & $28.5 \pm 0.5$ & $48.5 \pm 1.4(600 \mathrm{C})$ & undetermined & undetermined \\
\hline [octafluoroimid] $\left[\mathrm{Tf}_{2} \mathrm{~N}\right]$ & & $26.1 \pm 1.5$ & & undetermined & undetermined \\
\hline \multicolumn{6}{|c|}{ Ethylene } \\
\hline$[\mathrm{hmpy}]\left[\mathrm{Tf}_{2} \mathrm{~N}\right]$ & $52.7 \pm 7.5$ & $58.9 \pm 2.3$ & $77.8 \pm 3.3$ & $-8.5 \pm 1.7$ & $-27.7 \pm 5.4$ \\
\hline \multicolumn{6}{|c|}{ Ethane } \\
\hline$[\mathrm{hmpy}]\left[\mathrm{Tf}_{2} \mathrm{~N}\right]$ & $57.7 \pm 6.2$ & $76.2 \pm 4.2$ & $95.9 \pm 4.9$ & $-8.6 \pm 1.9$ & $-28.0 \pm 6.1$ \\
\hline \multicolumn{6}{|c|}{ Methane } \\
\hline$[\mathrm{hmpy}]\left[\mathrm{Tf}_{2} \mathrm{~N}\right]$ & $441.2 \pm 79.1$ & $418.9 \pm 33.6$ & $420.2 \pm 100.0$ & $1.0 \pm 5.7$ & $3.3 \pm 19.0$ \\
\hline$[\mathrm{hmim}]\left[\mathrm{Tf}_{2} \mathrm{~N}\right]$ & $379.9 \pm 28.8$ & $402.6 \pm 22.3$ & $534.9 \pm 127.0$ & $-4.4 \pm 3.6$ & $15.0 \pm 12.2$ \\
\hline \multicolumn{6}{|c|}{ Oxygen } \\
\hline$[\mathrm{hmpy}]\left[\mathrm{Tf}_{2} \mathrm{~N}\right]$ & $1135.1 \pm 94.4$ & $803.0 \pm 30.4$ & $725.0 \pm 225.7$ & $14.2 \pm 3.9$ & $47.9 \pm 13.3$ \\
\hline$[\mathrm{hmim}]\left[\mathrm{Tf}_{2} \mathrm{~N}\right]$ & $992.5 \pm 106.0$ & $875.8 \pm 68.0$ & $1104.9 \pm 253.64$ & $0.5 \pm 4.4$ & $1.32 \pm 14.8$ \\
\hline [hmim][eFAP] & & $602.6 \pm 62.4$ & $2667.5 \pm 2194.5(600 \mathrm{C})$ & undetermined & undetermined \\
\hline [hexafluoroimid] $\left[\mathrm{Tf}_{2} \mathrm{~N}\right]$ & & & $952.6 \pm 473.5(600 \mathrm{C})$ & $21.2 \pm 1.7$ & $69.5 \pm 5.6$ \\
\hline \multicolumn{6}{|c|}{ Nitrogen } \\
\hline$[\mathrm{hmpy}]\left[\mathrm{Tf}_{2} \mathrm{~N}\right]$ & non-detect & non-detect & $23760 \pm 2339.6$ & undetermined & undetermined \\
\hline$[\mathrm{hmim}]\left[\mathrm{Tf}_{2} \mathrm{~N}\right]$ & & non-detect & & & \\
\hline [hexafluoroimid] $\left[\mathrm{Tf}_{2} \mathrm{~N}\right]$ & & $892.3 \pm 287.2$ & non-detect & undetermined & undetermined \\
\hline \multicolumn{6}{|c|}{ Hydrogen } \\
\hline$[\mathrm{hmpy}]\left[\mathrm{Tf}_{2} \mathrm{~N}\right]$ & & non-detect & & undetermine & ermined \\
\hline
\end{tabular}


Henry's Law Constants for various ILs at $25^{\circ} \mathrm{C}$

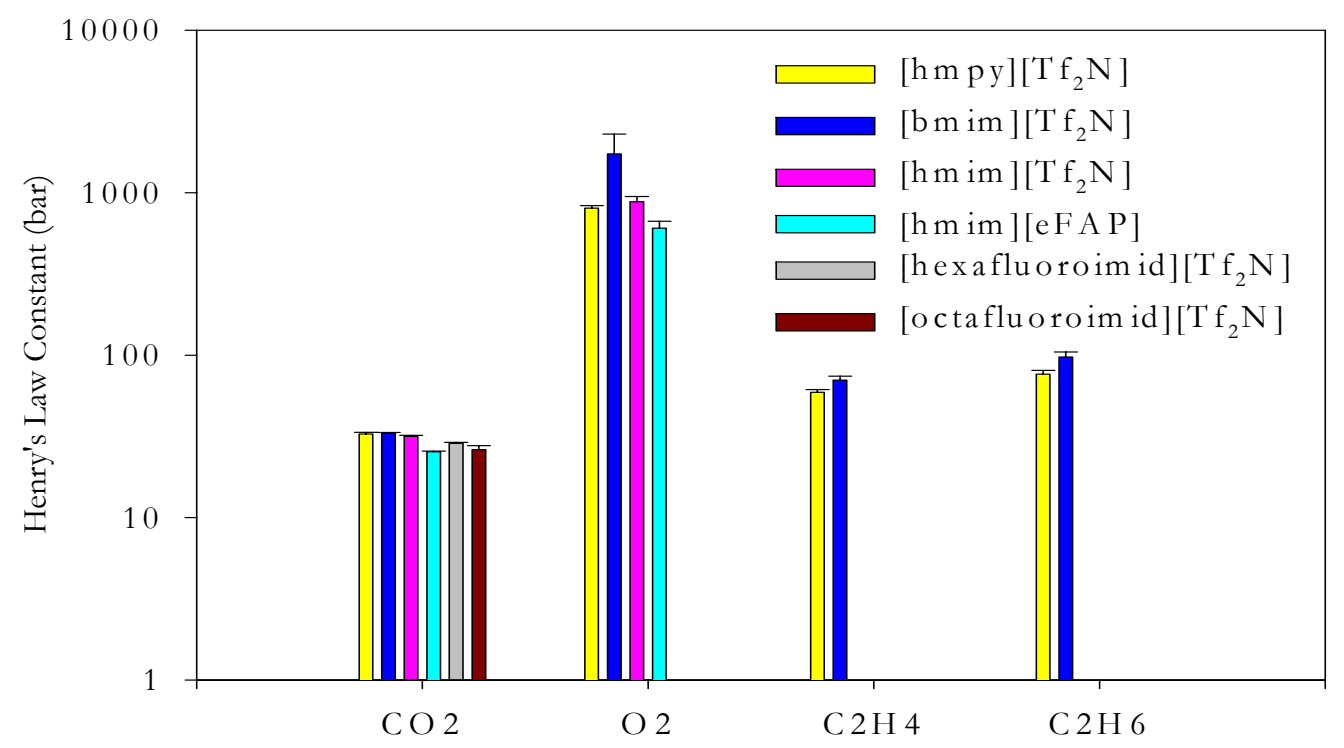

Figure 5: Graphical representation of the experimental Henry's Law constants.

\section{Simulations}

To simulate gas solubility in ionic liquids, we have had to develop a new simulation method that incorporates variable solute concentrations coupled with appropriate simulation of the condensed phase. The statistical mechanical ensemble consistent with this formulation is the $\mathrm{N}_{1} \mathrm{f}_{2} \mathrm{PT}$ ensemble, in which there are a constant number of ionic liquid molecules $\left(\mathrm{N}_{1}\right)$, a constant gas phase fugacity of the solute $\left(\mathrm{f}_{2}\right)$, constant total pressure and constant temperature. To perform these simulations, we have to develop and test new software that can perform these calculations. We have worked on the algorithm and written several of the new subroutines required. We anticipate that the software development and testing phase will continue for 3-6 more months before the software is robust and optimized enough to perform the calculations that are required.

\section{Conclusion}

We have initiated a study aimed at developing an understanding of $\mathrm{CO}_{2}$ solubility in ionic liquids. The project involves synthesis of new compounds, experimental measurement of physical properties relevant to application of these liquids in $\mathrm{CO}_{2}$ sequestration efforts, and molecular modeling. The goal is to develop ionic liquids that can be more effective (technically and economically) than conventional absorbents such as amines.

During the last quarter, we have synthesized several new compounds and started measuring densities, viscosities and gas solubilities in a number of the compounds 
acquired during the first quarter. These properties are essential for assessing the viability of these compounds for $\mathrm{CO}_{2}$ sequestration. From these experiments, we are beginning to develop an understanding of the factors responsible for high $\mathrm{CO}_{2}$ solubility. We are ahead of our schedule originally developed for the project.

\section{References}

Aki, S. N. V. K., Mellein, B. R., Saurer, E. M. and Brennecke, J. F. (2004) Journal of Physical Chemistry $B$, In Press.

Anthony, J. L., E. J. Maginn, et al. (2001). "Solution thermodynamics of imidazoliumbased ionic Liquids and Water.” J. Phys. Chem. B 105: 10942-10949.

Bates, E. D., Mayton, R. D., Ntai, I., Davis, J. H. JACS, 2001, 124, 926

Macedonia, M. D.; Moore, D. D.; Maginn, E. J.; Olken, M. M. Langmuir 2000, 16, 38233834. 